\title{
Sensitivity Analysis of Sediment Transport in Karun River
}

\author{
Mehdi Delphi, Mohammad Mahmoodian Shooshtari and Hooshang Hassoni Zadeh
}

\begin{abstract}
Shoushtar city is a coastal one why includes a big part of the Karun river and has many water uses; so the crevasse canal of the Gar-Gar as an artificial and manmade branch of the Karun, the biggest river in Iran, and in Shoushtar domain is started in place of the setting dam, Band-E-Mizzan, and it devotes 0.1 (according to seasonal measurements averaged) of water volume flowing in the Karun route before the setting dam controlled by the 9 setting windows on the dam. Water current as volume of water, transport water and so sediment particles to other places in route of river canal. Widespread currents through width of river canal transport sediments and coastal erosion in coast lines that are influenced by topography and steepness of river canal. In this research after continuous and regular measurements in two warm and cold seasons (winter and spring of 2009) and comparing with the data collected by zonal water and electricity organization, Khuzestan state (for calibration of the measurements), contours of dominant current in the river width and widespread current with measured current spectrum around the setting dam will be drawn, then effective factors in forming dominant currents will be appointed there. The effective factors on destructiveness of currents in coastlines of the river with a meanders in it will be an applied and useful result of this paper.
\end{abstract}

Index Terms - Karun river, water current, sedimentation, environment..

\section{INTRODUCTION}

Karun River as the biggest watery river basin after reaching to Shoushtar at area of Takht-e-Qeysar and passing of an arc path (meander) passes about one kilometer. The study of flows and sediments debies in this area because of centrifugal force has significant importance. Since in meander of river because of effect of centrifugal force, there are different deby sediments and currents model and have eddy or whirlpool structure so the coastal line destroy in this coastal line and width of river would be extended Studying water currents in different basins such as rivers, straits and bays have been important as a result of valuable matters in scientific features. When a canal of water current is direct without any unstraight, water body moves calmly, only a mild damping rate in time and space. Civil engineer and water engineering problems about a water basin will be resolved studying current, sediment debies and these are related to the environment around water basin; so it is

Mehdi Delphi, Ms.C student in Civil engineering, Islamic Azad University, Shoushtar Branch, Iran

Mohammad Mahmoodian Shooshtari, Faculty member, Islamic Azad University, Shoushtar Branch, Iran

Hooshang Hassoni Zadeh, Faculty member, Islamic Azad University, Shoushtar Branch, Iran necessary to study and research more and more in water basins like rivers what are in direct effect one human life in coastal cities and ports. Gar-Gar, a crevasse of the Karun river is started in Shoushtar city and connects to Shotteit, another crevasse of the Karun in Band-e-Ghir. The Karun River is the biggest one in Iran [1]. Sedimentation and coastal destruction are two important phenomena about hydraulics of river; People living around rivers in coastal cities are influenced from these water basins [2]. Of course in the Gar-Gar, two factors cause to decrease sedimentation rate in coastline and then coastal destruction is decreased in coasts of this river. Knowing about methods and ways to protect coasts of river in ports and coastal cities, people would be safe from dangers due to flood and wetland progress into floodplain. In fact turbulence effects and so coastal destruction will be resulted when current has had an eddy form, as is mentioned in [6]. Therefore in the mankind direct canal for Gar_Gar with straight rout for water flow in spite of the Shotteit including a meander as an arc of a circle, there is no considerable coastal destruction in it.

\section{Current Simulation}

Simulation means behavior modeling. Simulations include physical and mathematical ones. Dominant equations are the subjects studied in the above two type of modeling. Current simulation in physical type needs boundary conditions in water canal. Physical modeling or simulating currents in a river or water basin is done running a computer code. In this research, running a code Fortran would be the main tool simulating current behavior in the Karun river, shoushar domain. Finally, curves and contours of the currents will be drawn by femlab. Horizontal pattern of it will be resulted as current velocity profile. Sedimentation in a water canal like a river is influenced through current of water. Sediment particles transport is done associated with water flowing.Much study is done with measurements and observation in the case zone (the Karun River). Measuring water currents and sedimentation rates annually are registered. That is, coastal destruction and castling destroy are important that are studied about quality and quantity valuing. Bottom friction and lateral stress as two decreasant forces on water currents and sediment particles moving in water canals affect negatively. Because water velocity would be weakened and debies would be affected and weakened. Some useful and applied photos about the subject of this research in a direct and an indirect river canal are taken as follow as below. 


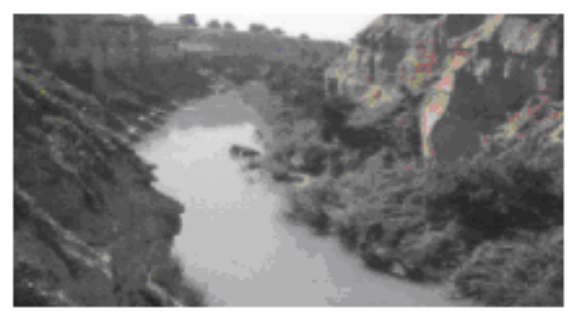

Fig.1 Route of the Gar-Gar canal straightly

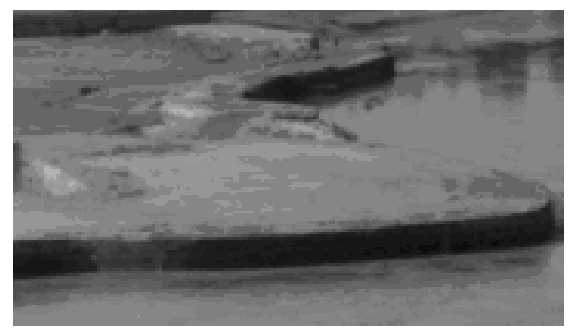

Fig.2 Sinusoidal shape of the Band-E-Mizzan

So current pattern in a meandering water canal would be complicated with damages to coastline while there is no considerable coastal destruction or destroy in a direct water canal without existence of centrifugal force effects.

\section{TwO FUNDAMENTAL FACTORS}

As it was mentioned before in this paper, two main and natural factors around the Gar-Gar which help to decrease sedimentation rate and o coastal destruction would be minimized much. First, the direct route of the water canal in Gar-Gar guarantees avoiding any meander for water flowing through it. By this, there wouldn't acceleration for water motion in Gar-Gar. Second, coastal walls in two sides of the gar-Gar river are made by rock and stone. In fact, rocky walls in two sides of it are fasten to resist against water currents [3]. Therefore sedimentation in coastlines would be minimized as much possible. Fig.4 show stone walls around the Gar-Gar in Shoushtar domain and direct route of it, respectively.

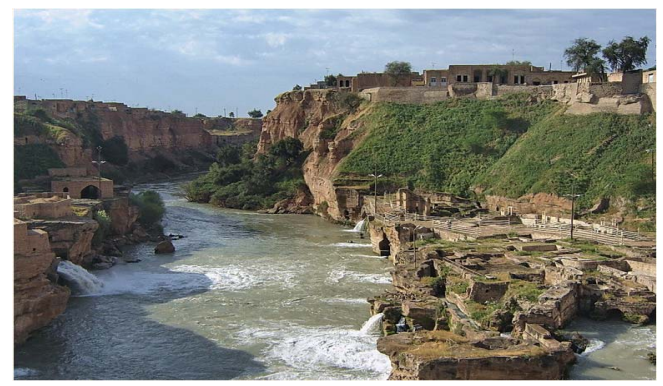

Fig.3 Stone and rocky wall of the Gar-Gar

After data arrangement collected in the zone, sedimentation and current debies analyse were studied; Diagrams needed appropriately for this reason were got from Dadisp graph software. That is, spectrums of the dominant water current and sedimentation rate for the Karun River, Shoushtar domain, are defined and recognized by the following two spectra.
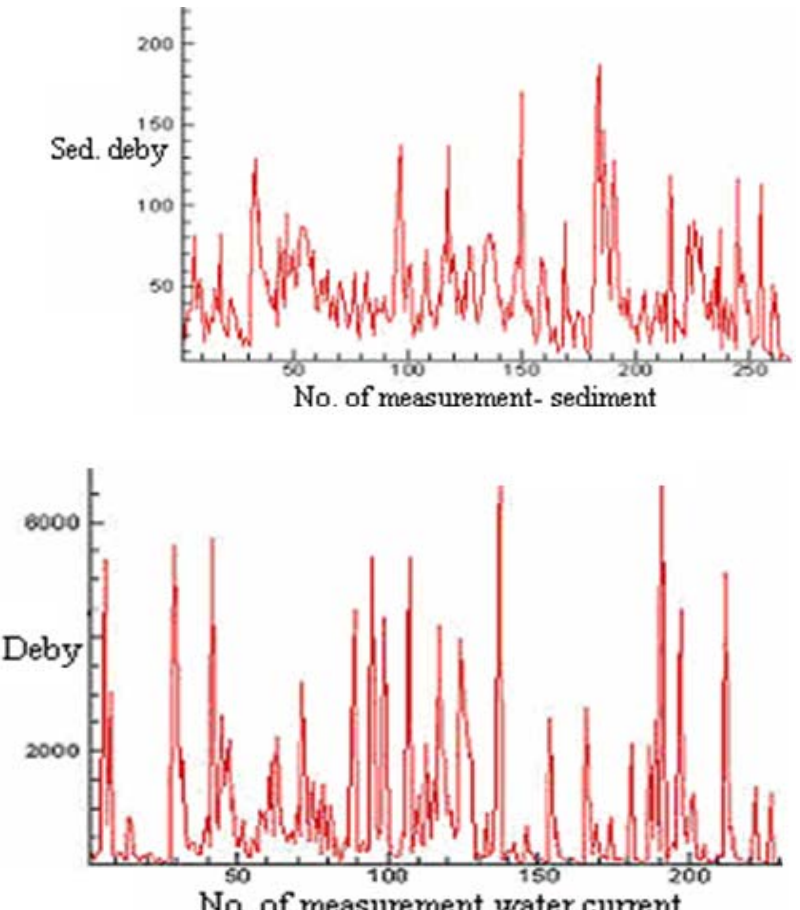

Fig.4. Spectrums of deby of sedimentation and water current

As we can observe in the above two diagrams, as a result of much raining in winter rather than in summer, they have usually top extermums in cold with rain season of year. Furthermore in a canal with a direct rout for water, current velocity has a uniform and rather homogeneous profile like the below.

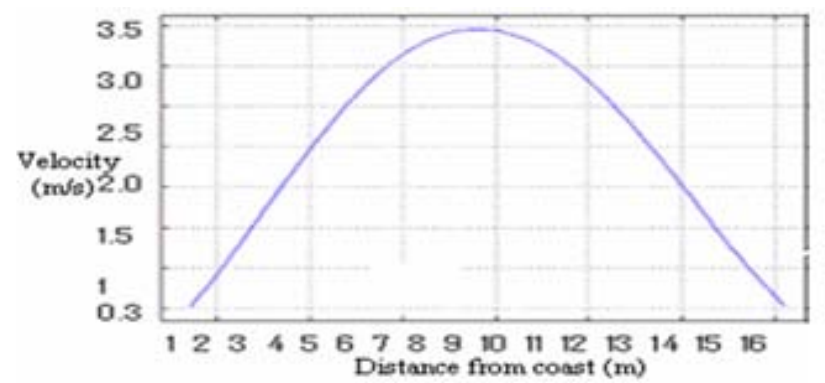

Fig.5. Profile of horizontal currents in the Karun river

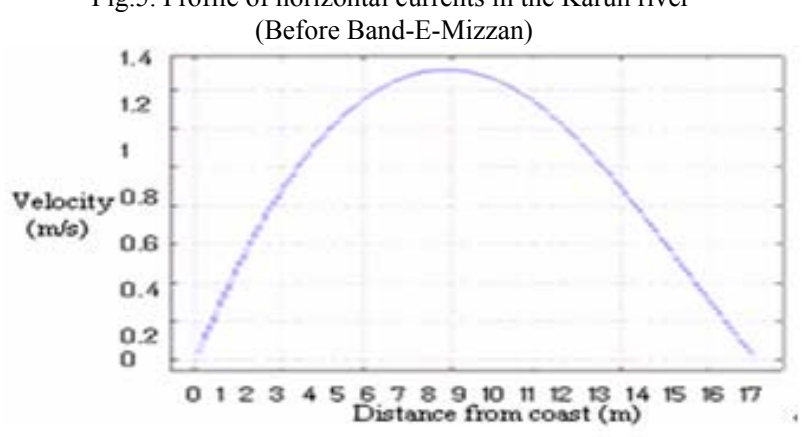

Fig.6. Profile of horizontal currents in the Karun river (After Band-E-Mizzan)

Studying boundary conditions and getting bathymetry of the Case River and using winter and summer data, dominant current modeling resulted. Overally, the picture of surface pattern of currents would be as the following photos on the 
surface. That is, we could see ripples on it even when wind blowing on.

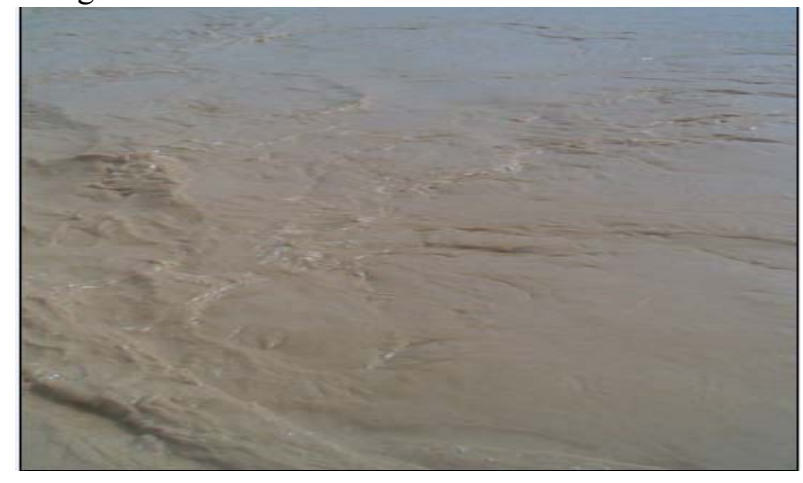

Fig.7 The surface calm pattern of current for the Gar_Gar water canal

\section{Two Type Of RIVER CANALS}

The Karun River, as the biggest one in Iran has two branches in some cities of Khuzestan state like Shoushtar named the Shotteit and Gar-Gar ones. The Gar-Gar branch has a direct rout of water in spite of the Shotteit with a meander on it. Eddies exist on surface pattern of currents in the Shotteit as a result of centrifugal force; coastal destruction and sedimentation rate will be increase in this zone. In the Gar-Gar due to directly rout of water current and no stress mechanically on it, we see calm currents in the canal. It could be shown and the applied result would be compared for the above two types of water canal in the Shotteit and the Gar-Gar branches.

\section{Centrifugal ForCe}

When a thing is moving around a center for its circular motion, we can say it has a circular rotation [7].force accelerating it from the center which absorbs rotating thing is called centrifugal force. In base of rotation frequency as time scale of each complete circulation around the center $(\omega)$ or a fixed velocity of the thing, acceleration of it would be calculated by the following formula.

$$
a=\frac{V^{2}}{r}=V \omega=r \omega^{2}
$$

Which $r$ is the radius of circle as fixed motion rout of the thing. Whenever a canal has a circular rout as a piece of a circle, the centrifugal force is applied from the center of it on water current thus sedimentation particles moving associated to water flowing through the canal are accelerated under this force.

In the Karun river rout, Shoushtar domain, we observe an arc as a piece of a circle for canal of water. Therefore centrifugal force couldn't be negligible. In Fig.8 it is observed in a satellite picture.

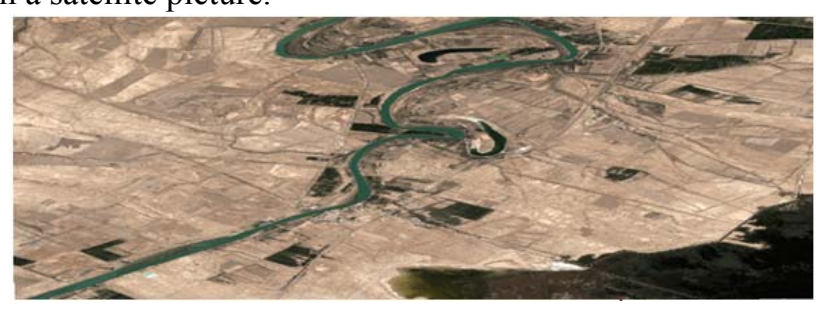

Fig.8 A satellite map of the area with Karun River and its branch Gar-Gar passing the Shushtar city

Concentrating on the diagrams we could get applied results. Using the applied results mentioned a below, hydraulical and hydrological principles important in water structures have been gotten in civil engineering. Shore protection and coast management is a basic and useful in ports and coastal cities. However we should be able to apply basins of surface water in life in optimum and efficient ways [4]. Surface water on the earth and atmosphere are two components of the double system important for weather change [5].

\section{RESUlt AND Discussion}

Study and development of civil engineering and structure architecture are important in using improved water resources for being efficient in life and progressing industry, agriculture and production too. Water and its resources such as surface water can be useful removing some needs of mankind. Programming, management, control and continuing considering about them are water engineering train in improving water resources and using usefulness of the matter. These items under a specialist team will be done more applied. However, avoiding from sweeping away water flowing in canal, penetrating into the coastal walls and water extension to floodplain are some material resulting from an optimum aqua management. River basins as secondary water bodies canal are among lands. If lands around rivers would be stable without slip and river direction is straight, sedimentation rate in coasts of river will be the most little. River basin under conditions that there wouldn't be floodplain, flood so sedimentation wont be considerable. According to the deby profiles, we could see maximum sedimentation deby in March. It is resulted from maximum fall so more water body in canal then. In the meander of river whirlpool or eddies are seen on the water surface, because of centrifugal forces effects from center of path curvature as an arch from a circular path. As a result rotator or secondary streams between two coastal lines in meander lead to transferring of sediments ingredients and increasing of sediment rate, destroying and internal erosion. So establishing resistant and waterproof coastal or rock or stone walls (sheet pile and...) along to coastal line in meander of river in indispensable. Also continues monitoring of streams profile model, reciprocal effect of river streams and coastal lines should studied, evaluated and managed. Other interesting point is that in the meander of river because of centrifugal and accelerative force, the acceleration of sediment particles and dominant stream would increase, finally vortex secondary streams in river lead to coastal sediment and therefore destroying of coast. In the location under study of this research, establishing the regulative dam Band-E-Mizan and existing water control valves and directing it from that $(0,1$ of the total stream) to secondary channel and artificial lead to decreasing the amount of sediment rate and coastal destroying. River basins as secondary water bodies canal are among lands. If lands around rivers would be stable without slip and river direction 
is straight, sedimentation rate in coasts of river will be the most little. River basin under conditions that there wouldn't be floodplain, flood so sedimentation wont be considerable. According to the deby profiles, we could see maximum sedimentation deby in March. It is resulted from maximum fall so more water body in canal then. The most important factors for decreasing sedimentation rate in river basin are as below. We could get useful and applied results from researches like this article such followed notes:

1) Direction of setting dam should be straight in ratio to water currents of river for entrance after dam to optimize the efficiency that related to their structure.

2) Numbers of windows and gates on setting dam must be appointed correctly to apply exact control water body flowing in river or canal after setting dam.

3) Building of setting dam and establishing of the second canal in place of maximum curvature of river is an applied task to decrease the rate of sedimentation and bank erosion.

4) Fastening bank lines of river, building of river coastal walls and deepening of the river basin would be useful to avoid happening of flood around river.

5) Materials for building of coastal structures must be appointed resistant rather than water.

6) Flood currents and sedimentation in the river with high current velocity could be controlled by setting dam creation.

7) Superposition of surface waves and secondary flows with dam structure mouths can lead to decrease erosion and make a calm river.

8) Establishing an artificial water way as a canal in the meander of river.

\section{ACKNOWLEDGMENT}

We thank water and electricity organization in Khouzestan state for providing the data used in this study. Also special thanks to my precious professors, Gentlemen Mahmoodian Shooshtari and Hassoni Zadeh for help.

\section{REFERENCES}

[1] Alleyassin A., (1995), Application of river engineering, Iran

[2] Mosaddad S.M. and Akhyani M., (2007), Coastal destroy due to river bending and drift of sedimentation due to piers. In: Proc of the Hydropower2007 International conference, Kandy, Sri Lanka, (2007), pp121-126.

[3] Mosaddad S.M., Akbari Bidokhti A.A.and Ezam M., (2008), Current modeling considering civil engineering problems building coastal walls. In: Proc of the Fluid Mechanics Asian congress, Daejeon, South Korea, 2008, pp 234-241.

[4] Delphi M., Mosaddad S. M., (2010), Physical modeling of water current in Karun River, Shoushtar domain, Journal of environmental Science and Development, 2010, 4p.

[5] Shames, H,. (1999), Mechanics of Fluids, London, pp: 150-240.

[6] Samuels, P. et al., (1889), Methodology for conveyance estimation in two-stage straight, slewed and meandering channels, $11 \mathrm{p}$

[7] Venyagamoorthy, S. and O. Fringer, (2005), Nonhydrostatic and nonlinear waves, Geophys. Res. Let., 32, doi: 10.1029/2005GL023432 